\title{
A National Conference for Collaboration in Engineering Education
}

\author{
Ronald Ulseth, Kenneth Gentili, Aaron Wenger Amy Hendrickson, Scott Klingenstein, \\ Jim Richardson, Paul Gordy, Nick Nicholson, Thomas Grace, Don Moen \\ Itasca Community College / Tacoma Community College / Itasca Community College / \\ Eveleth Gilbert High School / Bismarck State College / University of Alabama / \\ Tidewater Community College / Central Alabama Community College / Broome \\ Community College / University of North Dakota
}

Starting with the "George Report" to NSF in 1996 it has become increasingly clear that Two-Year Colleges (TYC's) could play a major role in engineering education. Community Colleges generally enjoy recruitment privileges among high schools that are difficult to duplicate at the university level. They also may be somewhat better able to incorporate retention producing instructional practices at the critical freshman and sophomore level of engineering education than is practical in a much larger university environment. The issue of under-represented groups in the engineering pipeline may find practical solution through the familiar access point to engineering of a community college.

There are problems to be addressed if TYC's are to contribute in any major fashion to engineering education in America. First and foremost is the simple fact that many TYC's have little or no history of committing to a two year sequence of engineering curriculum. Many, in fact, have trouble committing to a complete calculus sequence or to calculus-based physics. In addition, there is the difficulty of good articulation agreements that ensure seamless transfer of two year's worth of engineering classes between TYC's and universities. A few states, in fact, by law make such transfer impossible.

However, the opportunities for increased recruitment of both traditional and under-represented groups to the educational track leading to an engineering career that are afforded by the community colleges of this nation may be too large to continue to ignore. The possible increased opportunities for retaining a larger percentage of beginning students to an engineering track possible in the small, instruction-driven classes of a TYC may also be too important to ignore. It may just be that the time is ripe to take a look at creating a coherent pathway to an engineering career that begins in the local community with a community college and that ends in an engineering degree from an ABET accredited university. Past work by the authors with a national group of TYC physics educators (TYC-21, an NSF funded program) found great interest among TYC physics instructors for redesigning physics instruction to better fit the needs of engineering students. The authors own success in creating an engineering collaboration that now moves nearly 50 engineering majors into junior level work each year, may be the catalyst that is needed to begin a national collaboration between TYC's and universities that enhances engineering education. Our paper will detail the current work of the authors, supported by NSF, in arranging for a national conference to explore TYC-University collaboration for engineering education. The national conference will have as its goals:

\section{Goals:}

A. Create a National Collaboration for Engineering Education (NCEE). This collaboration would focus national attention and resources upon Two-Year College (TYC) involvement in engineering education. It would foster articulation between TYCs, Universities, and High Schools. It would bring attention and resources to the unique position that TYCs hold as connectors of high school teachers in SMET and universities offering engineering degrees. The TYCs are the logical connector between high school math, science, and technology teachers and engineering degree granting universities. TYCs often have deep roots within the local community, local businesses, and within the local school districts that can be used to recruit and retain students successfully to the educational pathway leading to an engineering degree. 
B. Through a national collaboration increase TYC participation in engineering science programming and increase University to TYC articulation for engineering education.

C. Increase by $50 \%$ the number of TYCs seeking funding for articulated engineering programs.

D. Based upon the ICC success with articulation, recruiting, and retention efforts the national collaboration should expect to increase engineering enrollment within participating TYCs by at least $100 \%$. A greater percentage than ever before of first generation, female, Pell eligible, and minority students will enter the engineering pathway and will succeed.

\section{Overview:}

There is a general consensus that the nation's engineering workforce is in some jeopardy. It is not in jeopardy because of a lack of expertise or training. Indeed, America's engineers are leaders in R.\& D. in nearly every engineering field. It is not in jeopardy because of some lack of training received by engineering students in their education. Indeed, America's engineering universities continue to be the schools of choice for any foreign student lucky enough to be able to come here to study.

The jeopardy is that of too few young Americans ever even think about a career in engineering. The issue is also that of too narrow a cross-section of the modern American workforce seeking careers in engineering. The very nature of the diversity of engineering careers implies that the nation would be best served by a well educated, skilled, and personally diverse engineering workforce. We are also left with the commonsense issue that in a world with a $4 \%$ increase in needed engineers per year, there are simply not enough sons of doctors, lawyers, scientists, etc. to produce the needed numbers of professional engineers anticipated for the next few decades. Fewer students in our universities are entering engineering now than a decade ago. There appears to be a disconnection between most of our communities and the very real opportunities afforded by a career in engineering. "Dilbert" appears to be the public's perception.

Varying a bit from state to state, about 1965 there started in the nation a "middle-man" in education. It was the Community Colleges, or as they are often called, the Two-Year Colleges (TYCs). The TYCs serve many purposes from remedial classes, to workforce retraining, to recreational classes, to university transfer classes. They are generally commuting colleges with often over $90 \%$ of their students commuting each day to classes. Typically over $70 \%$ of their students have jobs of thirty or more hours per week. Usually, over $50 \%$ of their students come from only 2-3 "local" school districts. According to an informal polling of TYC instructors within the national group of TYC physics instructors known as TYC-21, fewer that one in ten TYCs offer any engineering science classes beyond calculus, physics, and chemistry.

Yet the TYCs offer a great potential to engineering in America. It is the authors' contention that TYCs are perfectly positioned to increase the awareness of engineering in our nation's high schools (especially to underrepresented groups) and that TYCs are a logical entry point to engineering if issues of curriculum, articulation, recruiting, and retention are addressed coherently. The proposed conference will bring together leading TYC engineering programs, transfer universities, and high school SMET teachers to begin the discussion of how a national effort can involve the TYCs in producing a new generation of engineers and technologists. A primary focus of the conference will be upon forming a collaborative effort between HSTYC-University for the recruiting and retention of students to engineering. A pre-conference planning meeting will be held with representatives from all areas of the collaboration. The pre-planning will result in a core set of HS-TYC-University articulation teams forming well before the main conference itself. This core group will set the details of the main conference's agenda. The main conference agenda will be built around recruiting, retention, and articulation as collaborative efforts between high schools, TYCs, and universities. The main conference will develop strategies to bring national attention and resources to making the nation's two-year colleges central to recruiting and retaining young people to the career of engineering. A follow-up effort, led by faculty of the ICC engineering program, will collect and amplify ideas coming from the conference into a Web-based library resource for all TYCs and universities interested in forming collaborative programs for engineering education. The conference and subsequent follow-up will also investigate forming a national collaboration (NCEE) to provide extended support to TYCs and universities interested in forming engineering collaborations and to promote the nation's TYCs 
as an important access point to engineering careers. Through such a national collaboration, engineering education and career opportunities can be extended to the audience of TYCs that is $70 \%$ first generation college, Pell Grant eligible, female, and/or minority. If indeed it is true that the engineering profession cannot any longer be staffed by just the sons of professional families, then a national collaboration aimed at moving TYCs to the forefront of engineering education is highly desirable.

At Itasca Community College we have been building an engineering program for over a decade. It started with the realization that our calculus physics should be taught as an introduction to the necessary analysis of engineering, not as a theory of physics course for one or two physics majors per decade. We customized the program further by building into it lab-centered instruction and student-design projects. We created a sense of ownership for the program by students and a very real support network via a student Learning Community. Our program now stands at the cusp of being the fifth largest in Minnesota through the statefunded construction of an Engineering Center building. The Engineering Center will include living space for 40 engineering students as well as integrated lab-classrooms, project space, and a business funded Concept Lab for small R\&D or fabrication projects. The Concept Lab will foster active, year-long collaboration between students and professional engineers from the business community. In 1983 the ICC engineering program enrolled 3 students in calculus physics. None became an engineer. In 2000 we had 55 freshmen engineers. For the past three years retention of the freshman class to engineering has been at or near $80 \%$. The program has had $100 \%$ success in the transfer of those students who complete two years with us. This has been accomplished with a student body $60 \%+$ of whom are first generation college, $50 \%$ of whom are Pell grant eligible, 50\% of whom scored 18-24 on the ACT, and 17 of whom out of 55 Freshmen are women. Among the two year colleges offering engineering, it would seem that the engineering faculty at ICC are a logical choice to lead the nation in a new collaboration for engineering articulation, recruiting, and retention.

\section{Objectives:}

1) By bringing together a national set of "teams" (TYC, University, and HS faculty) that can showcase strategies for program articulation, recruiting, and retention we will begin a Web-based library of faculty resources for collaborative engineering programs between TYCs and Universities. National Meeting held by July, 2002.

2) Through a systematic follow-up to the national meeting we will produce at least ten carefully articulated HS-TYC-University engineering programs to serve as national models. All of these national model sites will have curriculum, articulation agreements, recruiting, and retention plans Web-posted as a library resource to other sites wishing to form or extend engineering collaborations. Follow-up and Web postings available by Dec. 31, 2003.

3) Seek funding for a National Collaboration for Engineering Education. Core group from the first national meeting will organize NCEE and seek funding to hold at least three additional national conferences for further development and dissemination during 2002-2003. By late 2003 a selfsupporting, Web-based organization will be in place for dissemination of best practices in articulation, recruiting, and retaining for engineering collaboration between TYCs and Universities.

\section{ASEE Conference Report:}

By the time of the Montreal conference initial planning for the national meeting will have been accomplished. Ten to fifteen teams of two-year college, high school, university, and engineering profession people from around the nation will have drafted an action plan to investigate collaboration for recruiting and retaining young people to the career track of engineering. This same action plan will address strategies of how to actively intervene, through the collaboration of two-year colleges, high schools, and universities, in order to more effectively address the issue of greater student diversity in the career track of engineering. By the ASEE conference the national collaboration will have identified 10-15 collaborations around the country that are actively working upon recruiting and retaining students for engineering. We will present a preliminary report at the conference of those strategies.

We will report upon the national meeting and its success in setting up a national collaboration based around regional University-TYC-High School collaborations. As of this writing, one planning session has been 
held with a second to follow in Feb. Participation has been sought and found from professional societies, TYC's, Universities, and High Schools from coast to coast. ABET will be represented by Margaret Weeks. 